\title{
Variaciones en la menor: el retrato femenino en la narrativa modernista venezolana
}

\author{
Lise SeGAS \\ Universidad Bordeaux-Montaigne
}

Título: Variaciones en la menor: el retrato femenino en la narrativa modernista venezolana.

Resumen: El objetivo de este ensayo es estudiar la plasmación verbo-visual del discurso misógino finisecular enfocando la circulación de tipos de representaciones por diferentes campos del arte de entresiglos y tomando en cuenta la historicidad de dichas representaciones para proponer lo que Eric Mechoulan llama una "arqueología de los a priori" en el caso de los retratos femeninos finiseculares. Representadas, reproducidas en retratos pictóricos y literarios, las mujeres se coleccionan en galerías, según un proceso de museificación, que hacen de ellas objetos estéticos e ídolos deshumanizados, vaciados de su pluralidad, petrificados en una individualidad absoluta e irreal. Este trabajo explora una galería de tipos de retratos sacados de la narrativa venezolana modernista por una parte y por otra de la pintura de entresiglos (venezolana y europea).

Palabras clave: Mujeres, Pintura, Literatura, Venezuela, Modernismo.

Fecha de recepción: 11/10/2015.

Fecha de aceptación: 12/10/2015.
Title: Variations on Feminine Portraits in Venezuelan Prose Fiction.

Abstract: This paper analyses the pictorial and literary forms of the mysoginistic fin-de-siècle discourse and focuses on the circulation of some representations through different fields of turn-of-the-century art. It takes into consideration the historicity of such representations in order to propose what Eric Mechoulan calls an "a priori archeology" in the case of fin-de-siècle women's portraits. Depicted, reproduced in pictorial and literary portraits, women are collected in galleries, following a museumification process, which turns them into aesthetic objects and dehumanized idols, stripped from their plurality, petrified in an absolute and unreal individuality. This article explores a portraits gallery taken from modernist Venezuelan fiction in one hand and in the other from turn-of-the-century art (Venezuelan and European).

Key words: Women, Painting, Literature, Venezuela, Modernism.

Date of Receipt: 11/10/2015.

Date of Approval: 12/10/2015. 
Retrato, si eres sombra ¿cómo imitar al sol de más lucientes esplendores?

Muerto, ¿cómo están vivos tus colores?

Sin vida, ¿cómo tantas vidas quitas?

Sin cuerpo, muchas almas acreditas; sin alma, ¿dónde forjas los rigores? Si Clori es sin segunda en los primores, ¿cómo darle segunda solicitas?

Eres una apariencia que recrea (gozada de los ojos solamente), una ilusión alegre de la idea,

un engańo que finge en lo aparente, una ficción que el gusto lisonjea, mentira, al fin, que a la verdad desmiente.

Catalina Clara Ramírez de Guzmán (1611-1684), Obras poéticas ${ }^{1}$

Aunque lo deje pensar el título, no voy a hablar de música (otra de las artes que tiene una relación muy estrecha con la literatura a finales del XIX) sino de mujeres y sobre todo de representaciones de mujeres en producciones literarias y pictóricas finiseculares masculinas. Octavio Paz, en el apéndice del Laberinto de la soledad, escribe lo siguiente: "Entre la mujer y nosotros se interpone un fantasma: el de su imagen, el de la imagen que nosotros nos hacemos de ella y con la que ella se reviste" ${ }^{2}$. El objetivo de mi trabajo es tratar de revelar y desactivar algunos dispositivos del autofoco modernista gracias al que se solía -y se suele todavía- retratar a las mujeres.

No voy a presentar de forma pormenorizada la situación de las mujeres de entresiglos -varios trabajos, entre los cuales Las hijas de Lilith ${ }^{3}$ o el

1 Catalina Clara Ramírez de Guzmán, Obras poéticas, Sevilla, Muñoz Moya Editores Extremeños, 2004, p. 113. La primera edición de sus poemas fue realizada en 1930 por Joaquín Entrambasaguas.

2 Octavio Paz, El laberinto de la soledad, Madrid, Cátedra, 2012, p. 344.

3 Erika Bornay, Las hijas de Lilith, Madrid, Cátedra, 1990. 
famoso Idols of Perversity ${ }^{4}$ lo hacen muy bien- pero sí recordar que eran consideradas como menores de edad según la ley, como seres inferiores física e intelectualmente (pensemos en Schopenhauer ${ }^{5}$, en Lombroso ${ }^{6}$ o en $\mathrm{Nordau}^{7}$ ), y representaban, por consiguiente, una minoría -o menoría- en la sociedad en general y en el mundo artístico e intelectual ${ }^{8}$ en particular. El manto de plomo que cae sobre las mujeres encerradas por una sociedad patriarcal en un gineceo más o menos dorado es señal de un miedo masculino cada vez más intenso frente a la afirmación de subjetividades femeninas en los espacios laboral, social, político y cultural ${ }^{9}$. La misoginia finisecular es un hecho: la afirmación de lo masculino y la negación de lo femenino se entiende como la voluntad de mantener el orden social imperante que lo pone todo entre las manos de los hombres.

No obstante, como subrayan varios estudiosos ${ }^{10}$, la actitud del artista de entresiglos combina corrientes contrarias: su esquizofrenia lo hace oscilar entre el asumir orgullosamente la posición marginal que le atribuye la nueva sociedad burguesa que se impone -razón y justificación de su rebeldía- y el desear secretamente ser partícipe de la gran fiesta capitalista que transforma el arte en otra mercancía ${ }^{11}$ y que le permitiría vivir

4 Bram Dijkstra, Idols of Perversity: Fantasies of Feminine Evil in Fin-de-Siècle Culture, Oxford, Oxford University Press, 1988.

5 Arthur Schopenhauer, Essai sur les femmes, París, Mille et une nuits, 2005, 63 pp.

6 Cesare Lombroso, La femme criminelle et la prostituée, París, Ancienne Librairie Germer Baillière et Cie, Félix Alcan, Éditeur, 1895.

7 Max Nordau, Dégénérescence, París, Ancienne Librairie Germer Baillière et Cie, Félix Alcan, Éditeur, 1894, 2 vols.

8 No olvidemos a Juana Borrero (1877-1896, poetisa y pintora cubana), y a su hermana Dulce María Borrero (1883-1945, poetisa también), como ejemplos de artistas modernistas femeninas olvidadas por la crítica y la mayoría de sus contemporáneos (no por Julián del Casal, que frecuentaba el círculo de la familia Borrero, poetas de padre a hijo, y que escribió un poema-retrato de Juana: “Tez de ámbar, labios rojos..."), y a la uruguaya Delmira Agustini, que jugó mucho con la imagen modernista de la mujer como en su famoso poema "Serpentina" (1914).

9 Véase Erika Bornay, op. cit., pp. 83-89.

10 Entre ellos, podemos citar a Mireille Dottin-Orsini, Cette fermme quils disent fatale, Paris, Grasset, 1993, o a Maurice Belrose, L'époque moderniste au Venezuela: 1888-1925 (presse littéraire et roman) [thèse d'État], Lille, Université Lille 3, 1986, 3 vols.

11 Un cambio que se considera como una forma de "feminizar" el arte al situarlo en el centro de una relación compra/venta, de prostituirlo, según el código de valores modernistas. 
de sus creaciones ${ }^{12}$. El protagonismo novelesco que va adquiriendo esta figura torturada en la narrativa finisecular es una de las expresiones de ese dilema moral entre conservadurismo y modernización, vivido a veces como una verdadera enfermedad. Por cierto, el mantenimiento del orden parece, a primera vista, muy contrario a las veleidades de novedad y de libertad esgrimidas por los artistas modernistas, que se sienten desfasados con la sociedad finisecular. En ese contexto de crisis moral y artística, los jóvenes intelectuales vigorizan la idea de la juventud, reivindicando su protagonismo social, cultural y moral, que sella una separación con la generación anterior: basta leer Ariel de Rodó ${ }^{13}$ para entender el papel que se le atribuye a la juventud en el futuro de América.

La eterna juventud y el vigor artístico (masculino) como principio de la regeneración de aquellas sociedades se enfrentan sin embargo a un obstáculo: el de la feminización ${ }^{14}$ entendida como degeneración, según la teoría de Max Nordau, y, en ese posible mundo al revés, el de la masculinización de la mujer como suprema amenaza para jóvenes espíritus. El riesgo de la inversión de papeles que se manifiesta es peligroso porque los jóvenes artistas o intelectuales idealistas pueden caer en la trampa de la mujer fatal, que arruinaría sus proyectos (¿mujer fatal para quién? Para el hombre, por supuesto, porque es la que domina, la que asume el papel tradicionalmente masculino, la que ostenta una sexualidad agresiva, habitualmente viril, y la que libera su deseo para consumir una sexualidad del placer y ya no de la reproducción) ${ }^{15}$. O, dicho de otra manera, la mu-

12 Según una perspectiva sociológica de la literatura, se puede inferir que l'art pour l'art, la literatura considerada como un fin en sí misma, es un indicio del valor que se le quiere dar en el campo cultural a finales del siglo XIX y, de ahí, de la reivindicación de un estatuto particular para la figura del escritor (del que podría sacar un beneficio financiero o prestigioso).

13 José Enrique Rodó, Ariel, Madrid, Cátedra, 2000.

14 Paulette Silva Beauregard, "Una galería de mujeres: lecturas y lectoras en Venezuela a finales del siglo XIX y principios del XX", Revista Canadiense de Estudios Hispánicos, 28 (2003), pp. 215-239.

15 Pienso que se puede leer el arquetipo de la femme fatale como una reactivación del personaje de la bruja, según su concepción en el siglo XVII (que no fue la misma que en la Edad Media y el Renacimiento), en una época en que ya no se queman a esas mujeres que amenazaron a los hombres con sus poderes (saberes ocultos, sexualidad del placer, control del cuerpo, subversión del orden patriarcal, etc.) pero a las que se 
jer fatal como metáfora del deseo, base y principio de la nueva sociedad materialista, de consumo, que se va creando a finales del $\mathrm{XIX}^{16}$ y que va arrebatando los ideales espiritualizados de los modernistas. Deseo al que es difícil resistir, que amenaza el orden; deseo simbolizado perfectamente por Salomé, un ser-cuerpo infantil e irracional poseído por el deseo y que desafía el orden patriarcal simbolizado por la cabeza pensante perdida de un hombre-profeta ahora mudo -o castrado-.

$Y$ es cuando interviene la medicina o seudo-medicina que se interesa particularmente por la mujer y su cuerpo: solo mencionaré al famoso doctor Charcot para quien ser mujer es una anomalía, una enfermedad, cuando el hombre es la norma. A Charcot le gustaba elaborar catálogos de "têtes d'expression" (caras de expresión) después de estimular eléctricamente a sus pacientes femeninas -supuestamente catalépticas tras el "tratamiento"-; examinaba también en los cuadros de Rafael o Rubens las caras histéricas y se imaginaba como director y conservador de su museo, el hospital parisino de la Salpêtrière ${ }^{17}$. Medicina y escuelas de bellas artes estudian los mismos objetos. El control del cuerpo femenino -su dirección y su conservaciónes síntoma de la patrimonialización de la mujer: como un objeto más del patrimonio hay que conservarla porque es el vehículo de la transmisión.

En efecto, según las normas burguesas de la época, la función del hombre es la producción, la de la mujer la reproducción. Los filósofos como Schopenhauer, Nietzsche o Nordau se empeñan en teorizar la misoginia, los científicos - con los médicos entre los primeros- en biologizarla, los artistas

las estigmatiza bajo la forma peligrosa de la mujer emancipada. Véase Silvia Federici, Calibán y la bruja. Mujeres, cuerpo y acumulación originaria, Madrid, Traficantes de sueños, pp. 259, 262 y 264.

16 Luis Javier Martínez Victorio, "Decadentismo y misoginia: visones míticas de la mujer en el Fin del Siglo", en Mito y mundo contemporáneo: la recepción de los mitos antiguos, medievales y modernos en la literatura contemporánea, coord. José Manuel Losada Goya, Bari, Levante Editori, 2010, pp. 593-606. Según Luis Martínez Victorio, la mujer fatal aparece como la encarnación de los cambios generados por el modelo burgués que está triunfando (afición por lo material, el lujo, las apariencias -por cierto, muchas veces son actrices o mujeres hermosas las que juegan con su imagen y toman posesión de ella-) y como plasmación del deseo caprichoso, mientras que los artistas modernistas sueñan con ideales de libertad -del hombre-, con un mundo ideal en el que la mujer es la musa del artista y se somete a sus gustos.

17 Mireille Dottin-Orsini, op. cit., pp. 233-237. 
en estetizarla. La estudiosa norteamericana Ana Peluffo habla de "alianzas homo-sociales" ${ }^{18}$ consolidadas para contrarrestar el avance femenino. Yo voy a precisar la idea y hablar de alianzas homo-artísticas al concentrarme en las producciones de la pluma y del pincel, instrumentos fácilmente reivindicados como atributos fálicos. La fraternidad artística masculina se constituye con el fin de luchar contra lo que Rubén Darío llama "la abominable sisterhood internacional" 19 , el concepto de sororidad que se estaba desarrollando en el siglo XIX y que fue esgrimido luego por el feminismo de los años 1970.

La idea de este ensayo es estudiar la plasmación verbo-visual del discurso misógino finisecular, enfocando la circulación de tipos de representaciones por diferentes campos del arte de entresiglos y tomando en cuenta la historicidad de dichas representaciones para proponer lo que Eric Mechoulan llama una "arqueología de los a priori" ${ }^{20}$ en el caso de los retratos femeninos finiseculares. Representadas, reproducidas en retratos pictóricos y literarios, las mujeres se coleccionan en galerías, según un proceso de museificación ${ }^{21}$, que hacen de ellas objetos estéticos e ídolos deshumanizados, vaciados de su pluralidad, petrificados en una individualidad absoluta e irreal: y Dios - a la imagen del hombre, como bien lo glosaría Voltaire- creó a la Mujer o, en otros términos a la Menor, que no se puede crear sola, que no puede existir fuera de la mirada del hombre.

$* * * * *$

Para desarrollar e ilustrar mi reflexión voy a estudiar una galería de tipos de retratos sacados de la narrativa venezolana modernista, por una parte, y por otra de la pintura de entresiglos (venezolana y europea).

Los vínculos de la Venezuela de finales del siglo XIX con Francia fueron muy estrechos debido a las relaciones establecidas y mantenidas por el

18 Ana Peluffo, "Alegorías de la Bella Bestia: Salomé en Rubén Darío", en The Colorado Review of Hispanic Studies, Boulder, University of Colorado, 4 (2006), pp. 293-308.

19 Rubén Darío, "La mujer espańola", en Obras completas, Tomo XIX. España contemporánea, Madrid, Mundo Latino, 1917-1919. [Primera edición: París: Librería de la Vda. de Ch. Bouret, 1901], pp. 321-328.

20 Éric Méchoulan, "Intermédialités: le temps des illusions perdues", en Intermédialités, Montréal, Presse de l'Université de Montréal, 1 (2003), p. 19.

21 Idea que desarrollaré más adelante a partir de la reflexión del filósofo francés especialista en Estética, Jean-Louis Déotte. 
dictador Antonio Guzmán Blanco con el país galo, perfecto ejemplo del autócrata ilustrado afrancesado que ostentó el poder entre 1870 y 1890 con una alternancia ficticia gracias a presidentes títeres.

Además, Venezuela es un caso muy interesante porque fue un foco importante del modernismo: como recuerda Ángel Rama, el modernismo se desarrolla primero y sobre todo en la región del Caribe ${ }^{22}$, donde se nota más la influencia de los Estados Unidos y de su modelo económico y político. Sin embargo, cada país presenta una faceta particular de esta tendencia artística que mezcla corrientes contrarias y hasta contradictorias. En el caso de Venezuela, el modernismo es algo más tardío y se expresa sobre todo en la prosa y la prensa, según la tesis de Belrose. De hecho, desde Caracas se difunden dos revistas muy famosas: Cosmópolis, fundada en 1894 (hasta 1895) por tres grandes nombres del modernismo latinoamericano (Pedro Emilio Coll, Pedro César Domínici y Luis Urbaneja Achelpohl) y, sobre todo, El Cojo Ilustrado (1892-1915) 23, que divulgan la actualidad literaria y artística esencialmente francesa, proponen reseñas y bibliografías, y reproducen cuadros y obras artísticas. Muchos modernistas de la época colaboran con las dos revistas, sobre todo con El Cojo Ilustrado, que se difunde ampliamente por el mundo hispanohablante.

La circulación mundial acelerada por las revistas de los diferentes tipos de discursos, corrientes literarias y modas artísticas, participó en la apertura del mundo literario venezolano, y figuras como Manuel Díaz Rodríguez o Rufino Blanco Fombona eran admiradas del otro lado del Atlántico ${ }^{24}$ al formar parte de la gran comunidad intelectual y artística modernista.

El modernismo venezolano se caracteriza por una heterogeneidad considerable, diluyendo positivismo con romanticismo, naturalismo con de-

22 Ángel Rama, Rubén Dario y el modernismo, Caracas, Ediciones de la Biblioteca de la Universidad Central de Venezuela,1970, p. 27. Basta ubicar a los grandes nombres del modernismo para darse cuenta de ello: Martí y del Casal son de Cuba, Silva es de Colombia, Darío de Nicaragua, etc.

23 La revista le debe su nombre a la fábrica de tabacos de Manuel E. Echezuría, conocido como "el cojo" por su cojera. Gracias a su prosperidad, instaló una de las primeras tipografías de Caracas - contaba incluso con taller de fotograbado- de donde salió la revista que retoma dicho apodo, a modo de homenaje.

24 Unamuno escribió en El Cojo Ilustrado un artículo, "De la pseudo-poesía", 17, 239, (1901), pp. 744-746, y una reseńa, “Sangre patricia de Manuel Díaz Rodríguez”, 20, 265 (1903), pp. 12-13. 
cadentismo, criollismo ${ }^{25}$ con cosmopolitismo, e introduciendo dos debates fundamentales: por una parte, la cuestión de lo que es la literatura nacional y, más allá, la identidad nacional; por otra, la preocupación por el lugar que ocupa el artista en la sociedad venezolana de entresiglos en la que se suceden las dictaduras y se agudiza el problema de la libertad así como el del reconocimiento del artista. La reflexión que voy a proponer tratará más específicamente este segundo punto.

A través de un corpus compuesto por novelas y cuentos de Manuel Díaz Rodríguez, Pedro César Domínici, Pedro Emilio Coll y el menos conocido José Manuel Cova Maza ${ }^{26}$ (que viajaron a Europa a finales de los años 1890), y a la luz de algunos cuadros coetáneos, procuraré mostrar cómo las mujeres cristalizan las amenazas y angustias evocadas anteriormente gracias a un juego de correspondencias estéticas e ideológicas.

Los dos tipos o arquetipos que quiero estudiar circulan tanto por la literatura como por la pintura y se declinan en infinidades de avatares o variaciones. Son los siguientes: la mujer-florero (no la que decora sino la que es decorativa) y la mujer-modelo (no la que modela sino la que es modelada). Mi forma de proceder intentará ser la más clara posible: para establecer y aclarar la transposiciones de ideas y su plasmación estética, los ejemplos sacados de los relatos vendrán acompańados de una muestra gráfica.

\section{DE LA MUJER-FLOR A LA MUJER-FLORERO}

La tradición literaria, reforzada por la retórica mariana, suele asociar a las mujeres con las flores a partir de un simbolismo refinado ${ }^{27} \mathrm{y}$, a mi parecer,

25 Maurice Belrose, op. cit., p. 619, en sus tesis de Estado, define el criollismo como la valoración y la idealización del mundo rural venezolano y de los mantuanos, la vieja aristocracia criolla, y la condena de la nueva sociedad burguesa.

26 Manuel Díaz Rodríguez, Ídolos rotos, Madrid, Cátedra, 2009, [1ª edición: 1901]; Manuel Díaz Rodríguez, Sangre patricia, Caracas, Tip. J.M. Herrera Irigoyen \& CA, 1902; Pedro César Domínici, La tristeza voluptuosa, Madrid, Imprenta de Bernardo Rodríguez, 1899; Pedro César Domínici, El triunfo del ideal, Librería de la Viuda de Ch. Bouret, París-México, 1901; Pedro Emilio Coll, "El colibri", El Cojo Ilustrado, Caracas, V, 98 (15 de enero de 1896), pp. 96-98; José Manuel Cova Maza, Miriam de Magdala, Barcelona (Venezuela), Tipografía americana, 1911.

27 Lily Litvak, "Las flores en el modernismo hispanoamericano", Creneida. Anuario de 
algo despectivo. En efecto, si tomamos el caso al revés, podemos preguntarnos cuándo se observan correspondencias simbólicas entre los hombres y las flores, los árboles o cualquier otro elemento vegetal. Si existen ejemplos, serán puntuales (se conocen metáforas florales en la épica culta por ejemplo) pero absolutamente no reveladores de una tradición secular. Me propongo cuestionar el tópico de la vegetalización de la mujer como otro objeto de adorno -y que además se marchita- entre un florilegio decorativo que la ubica muchas veces en el jardín, este espacio de la naturaleza domesticada, o dentro de la casa, "envasada" en un espacio cerrado.

La mujer domesticada como ornamento del interior de la casa toma la forma de la hermana del protagonista de la novela de Manuel Díaz Rodríguez, Ídolos rotos (1901), precisamente llamada Rosa Amelia. Mujer decepcionada por la vida matrimonial, símbolo de juventud marchita, se pasa el tiempo cultivando rosas, begonias, campánulas y flores de Pascua en el jardín cerrado de las viejas quintas caraqueñas, o sea, transfiriendo en las flores cultivadas su vitalidad sexual frustrada y enclaustrada.

En El triunfo del ideal (1901), novela de Pedro César Domínici, el protagonista, el conde de Cipria, auténtico esteta italiano, contempla a María, joven sirvienta, "crecida en un jardín” ${ }^{28}$, que está preparando un ramo de flores para el aristócrata. Este último ve la escena a través de un filtro estetizante, según "su ideal de profeta artista"29, gracias al que visualiza a "Psiquis pastora, Venus jardinera, una griega del Guido"30 o, como precisa más adelante, "un cuadro de Watteau" ${ }^{31}$. La vegetalización de María es evidente en la cita siguiente, así como en el retrato realizado por el gran pintor venezolano en la misma época, Arturo Michelena, titulado Mariposa - Mujer con flores (Fig. 1), cuya fecha exacta se desconoce, y que ejemplifica muy bien la nueva floración de la naturaleza en la pintura finisecular y, más particularmente, de las flores:

A veces charlaba con las flores con tono de mal humor, reprendiéndolas por haberse vuelto feas, o agitaba febrilmente el pañuelo para ahuyentar

Literaturas Hispánicas, Córdoba, Universidad de Córdoba, 1 (2013), pp. 134-159.

28 Pedro César Domínici, op. cit., p. 6.

29 Ibidem, p. 61.

30 Ibidem, p. 62.

31 Ibidem, p. 65. 
las mariposas que la fastidiaban y la perseguían, acariciándola el rostro con sus alas de seda, dejando en sus mejillas sonrosadas finísimo polvo de oro [...]. Y la carga perfumada iba creciendo entre los brazos de la joven que paralizaba voluntariamente sus movimientos a fin de no marchitar a sus hermanas, las flores. $\mathrm{Y}$ eran deliciosos manojos de lilas de azul muy pálido, rosas desfallecientes, cálidas, tibias de aliento, olorosas a carne de mujer hermosa, iris de colores deslumbrantes, lirios inmaculados, claveles y heliotropos; y eran ramas sugestivas de citiso, de mimosas, de verbena; todo en una confusión de aromas y colores que embriagaba los sentidos e incitaba a un beso largo, a una larga caricia voluptuosa ${ }^{32}$.

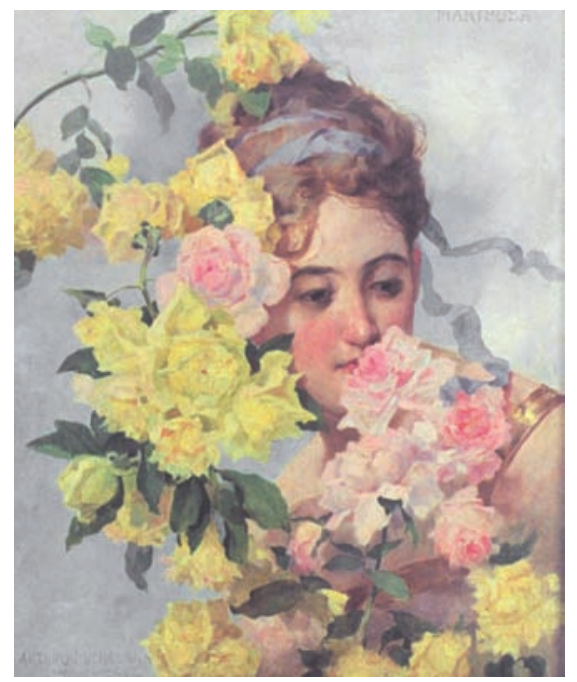

Fig. 1.

Sin revelar mucho de la intriga de la novela -que no deja grandes dudas sobre el desenlace-, el lector entiende que el conde va a coger la flor de esta joven belleza idealizada que, como en el retrato en el que las rosas rosadas acarician "las mejillas sonrosadas" y las amarillas se mezclan con la cabellera dorada de la joven, se confunde con las flores hasta volverse una planta más o un florero -un objeto vacío-, ya que el conde la observa mientras "en los vasos profundos de ancha garganta, iba ella colocando las flores" ${ }^{33}$. Más allá del simbolismo que se les quiera atribuir a los dife-

32 Ibidem, pp. 63-64.

33 Ibidem, p. 66. 
rentes tipos de flores, se nota que la profusión de colores y aromas excita los sentidos masculinos ${ }^{34}$.

En estas floralias se encuentran también las flores venenosas, las que hieren, las que enferman. En la novela de Manuel Díaz Rodríguez, Sangre Patricia (1902), la novia muerta del protagonista, Tulio Arcos, se transforma en los sueños reiterados de su joven esposo en "un gran lirio abierto sobre una montaña de rosas", un paisaje donde "se agitaron, como pétalos, dos labios por cuya curva de flor se deslizó el alba de una sonrisa" 35 , antes de transformarse en madrépora, contaminada por el elemento en el que reposa, el mar. Como bien subraya Rafael Alarcón Sierra, este episodio pudo haber sido inspirado por la novela de Huysmans, $\grave{A}$ rebours, en la que Des Esseintes sueña con una transmutación floral similar ${ }^{36}$. Los recuerdos de Belén, la novia de Tulio, se vuelven una obsesión irreal y fatal para el joven, que es irremediablemente atraído por el mar a fin de reunirse con su amada acuática idealizada, cuyo canto de sirena es irresistible.

Si desarrollamos la metáfora precedente, la flor inocente se cambia por una sirena atractiva y peligrosa, un motivo reproducido por el pintor prerrafaelista John William Waterhouse en su serie de Mermaids (1901 y 1900, Figs. 2 y 3) que representan respectivamente las dos facetas de la criatura marina: la belleza sensual (con el cabello rojo que aviva el deseo) y el peligro mortal para el hombre tentado por ella. En la novela de Díaz Rodríguez, se declina en Loreley ${ }^{37}$, idéntica a la "sorcière blonde" del poema de Apollinaire fechado en $1902^{38}$, hasta convertirse en monstruo al ser asimilada la pareja a los míticos Glauco y Escila ${ }^{39}$.

34 Este tópico artístico tiene tanta fama que el famoso establecimiento londinense Liberty of London de Regent Street, tienda favorita de los prerrafaelistas en el siglo XIX, lanza en los años 1920 los tejidos conocidos hoy por hoy como "Liberty" -lato sensu-, con motivos florales en miniatura, y que visten a las jeunes filles en fleur de la época.

35 Manuel Díaz Rodríguez, op. cit., p. 92.

36 Rafael Alarcón Sierra, "El destino del agua: Sangre patricia de Manuel Díaz Rodríguez", Cuadernos para la Investigación de la Literatura Hispánica, 20 (1995), pp. 7-29.

37 Manuel Díaz Rodríguez, op. cit., p. 161.

38 Guillaume Apollinaire, Alcools, París, Gallimard, 2000, pp. 99-101.

39 Manuel Díaz Rodríguez, op. cit., p. 190. 


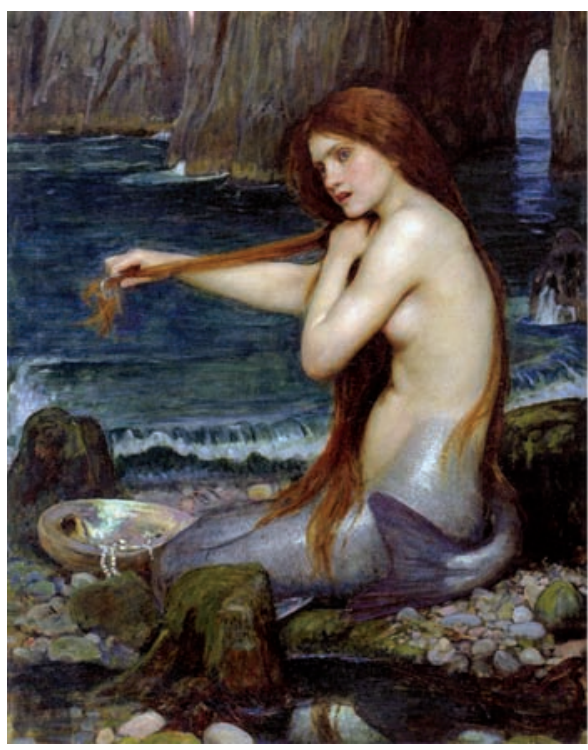

Fig. 2.

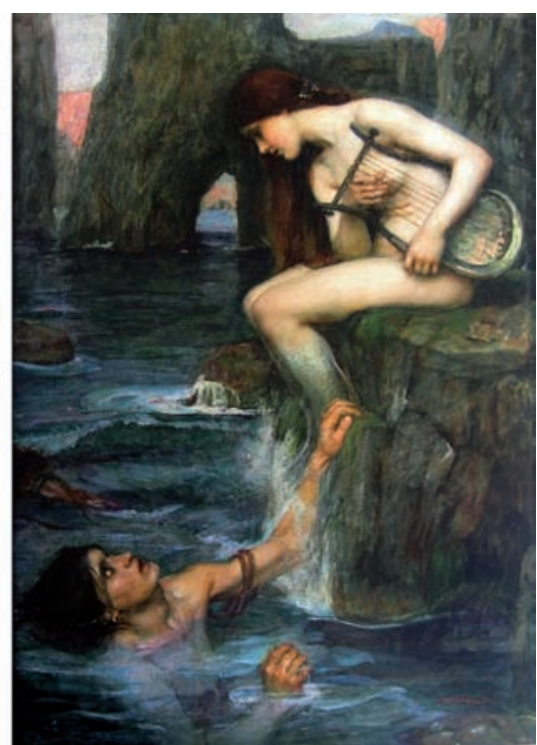

Fig. 3.

Para conjurar al monstruo y detener la transformación de la flor en nereida fatal, es preciso domesticar la flor y vaciarla de su esencia. En otra novela de Domínici, titulada La tristeza voluptuosa (1899), sale la mujer fatal parisina perfecta: Niní Florens (dotada de un nombre formado con la doble negación, como en la famosa canción finisecular francesa compuesta por Aristide Bruant "Nini Peau d'chien", y un apellido que remite a las flores). Niní es la encarnación por excelencia de la mujer hermosa, cruel, insensible, vacía, "la más fascinante y degenerada criatura" ${ }^{40}$. Mujer-percha que exhibe sus toilettes en el hipódromo de Longchamp, adornada con joyas, es una actrizcantante y una demi-mondaine muy cotizada (como la Nana de Zola -otro nombre que infantiliza-) que acompaña, como un trofeo, a sus amantes.

Sin embargo, es ella quien decide con quién va a salir y tiene un poder mortal sobre los hombres, ya que un amante suyo a quien había despreciado se suicidó "con el retrato de su insensible amada en el pecho" ${ }^{41}$. Por eso, es necesario actuar con ella con violencia (Eduardo Doria, el protagonista, llegará a pegarle) y considerarla como "una muñeca, con sus trajes muy cortos,

40 Pedro César Domínici, op. cit., p. 100.

41 Ibidem, p. 99. 
sus enormes sombreros extravagantes de plumas colosales y sus zapatitos de raso con grandes tacones" ${ }^{2}$, quitándole toda su humanidad, evacuando su realidad -algo más fácil con una mujer del mundo del espectáculo que se puede reducir a un ente de ficción-. Ya conocemos la fascinación de Toulouse-Lautrec y otros tantos pintores por las bailarinas, las cantantes o las actrices de los cabarés (como en el retrato de Nana, de Edouard Manet, 1877, Fig. 4), siempre representadas más o menos vestidas, como la muñeca a quien el rico amante pone o quita ropa, liviana (se observan las plumas del sombrero o del pájaro en el fondo), superficial (se ve en el espejo). Parece ser la única forma de tratar a Niní, una mujer sin corazón ni alma, porque "su mayor placer consistía en hacer sufrir o gozar a los hombres por su solo capricho, manejando los sentimientos como una máquina con ayuda de mańas y resortes" ${ }^{43}$. Mujer-muńeca, mujer-máquina, no estamos lejos de la L'Ève future de Villiers de l'Isle-Adam $(1886)^{44}$, novela en la que se construye una mujer-robot, gracias a Thomas Edison; una "androída” mucho más inteligente que el modelo femenino real y que obedece a su creador.

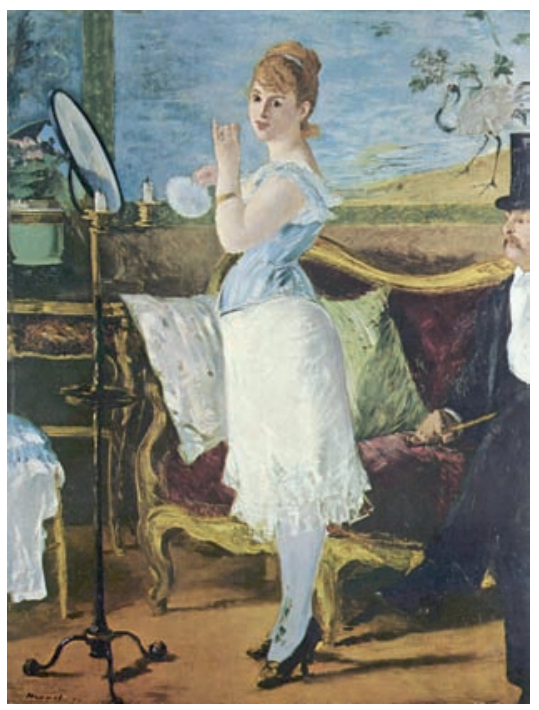

Ilustración 4.

42 Ibidem, p. 97.

43 Ibidem, p. 99.

44 Auguste de Villiers de L'Isle-Adam, L’Ève future, París, Gallimard, 1993. 
Dominar a este tipo de mujer "criminal” 45 (tomamos la terminología del criminólogo italiano Cesare Lombroso y su La mujer delincuente-traducido al francés como La femme criminelle-) implica vaciarla de su humanidad y reducirla a una superficie lisa, o sea, un retrato o el reflejo en un espejo (remito a los numerosos retratos de mujeres, venus o vírgenes con un espejo) o, peor, a una tapicería decorativa: es el caso en Ídolos rotos, de Díaz Rodríguez, cuando María, la novia oficial del protagonista, Alberto Soria, descubre el antro lujurioso donde se esconde con su amante Teresa Farías, reducida a "dos retratos [...] colgados de la pared" ${ }^{46}$, motivo que se reprodujo incluso en papeles pintados, como el ejemplo concebido en los EE.UU., en 1903, para cuartos de solteros (Fig. 5) ${ }^{47}$. Asimismo, Eduardo Doria de La Tristeza voluptuosa, evoca a su amante como a otro mueble decorativo, después de descuartizarla en una descripción física fragmentada que, como en todos los retratos femeninos canónicos, se detiene en las partes y no en el todo:

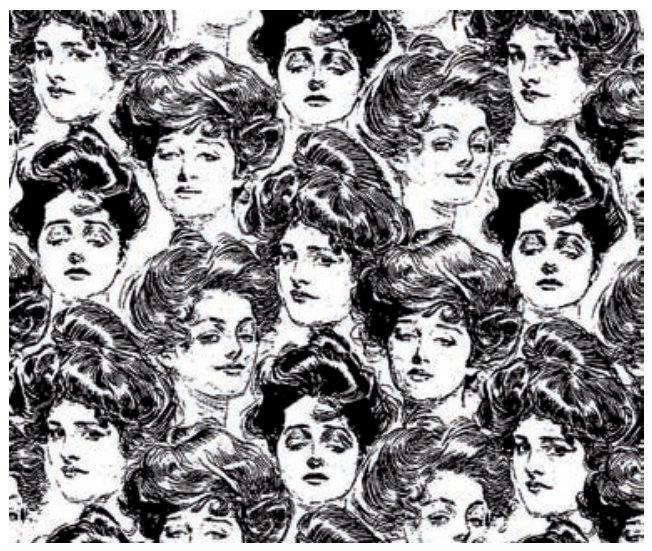

Fig. 5.

Después de amar el rostro, y los ojos, y la boca, y el cuerpo, terminamos por no amar sino los trajes de seda y los fondos de color, y las medias sutilísimas, y el calzado muy brillante, bien hecho, y bien llevado y luego, es peor todavía, se ama la alcoba y las cortinas de damasco, y los muebles raros ${ }^{48}$.

45 Ibidem, p. 105.

46 Manuel Díaz Rodríguez, op. cit., pp. 292-293.

47 Ilustración reproducida en Mireille Dottin-Orsini, op. cit., s. p.

48 Pedro César Domínici, op. cit., p. 105. 
Doria sigue con la evocación de Niní hasta convertirla en una bestia enigmática -bien sabemos que la mujer es el Enigma para el hombre, hasta Freud lo teorizó en aquella época ${ }^{49}$ - como la esfinge que excita tanto a Des Essseintes en $\grave{A}$ rebours $^{50}$ (una ventrílocua que ni siquiera tiene nombre y que imita a la esfinge de noche) como a Gustave Moreau en Edipe et le Sphinx (1864, Fig. 6) o a Fernand Khnopff (1896, Fig. 7): "Eduardo no amaba la mujer en Niní Florens; amaba la esfinge insensible y despótica" ${ }^{51}$. Una mujer-bestia desnuda que, como en el cuadro de Moreau -y a diferencia del de Ingres de 1827- toca al hombre de forma agresiva, colocando su pata en la entrepierna, como si fuera a castrarlo con su sexualidad desaforada. Toma el control, se vuelve la protagonista, hasta eclipsar a Edipo en cuadros posteriores (como el de Khnopff, en el que ocupa el centro del cuadro ${ }^{52}$, y aún más el de Franz Von Stuck de 1904, en el que la mujer pierde sus atributos animales mitológicos y aparece completamente desnuda, Fig. 8).

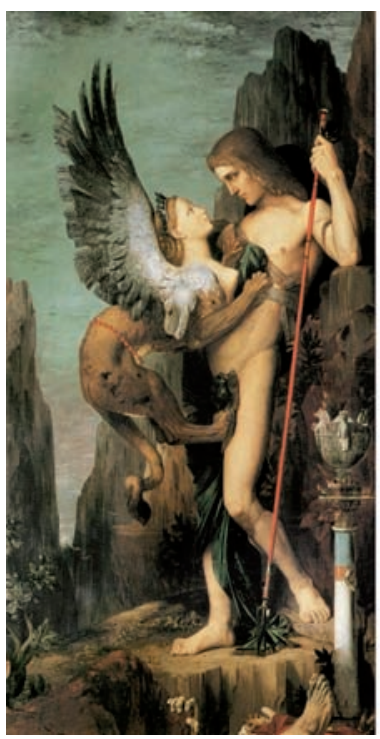

Fig. 6.

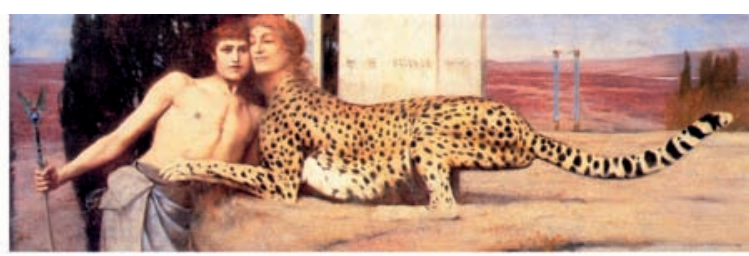

Fig. 7.

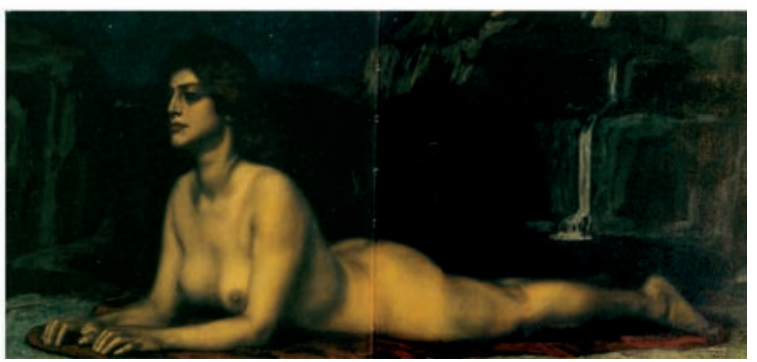

Fig. 8.

49 Sigmund Freud, Trois essais sur la théorie sexuelle, París, Gallimard, Folio, 1987.

50 Joris-Karl Huysmans, À Rebours, París, Gallimard, Folio, 1977, pp. 210-211.

51 Pedro César Domínici, op. cit., p. 106.

52 Se puede observar además el rostro femenil de Edipo, un hombre afeminado bajo el poder de la esfinge. 
De la mujer vegetalizada, animalizada -o totemizada-, robotizada, deshumanizada, a la mujer muerta, queda un pasito: la necrofilia es otra modalidad de representación de la mujer-florero que es mucho más interesante cuando ya no puede hablar. El protagonista de El triunfo del ideal solo ama a mujeres enfermas o condenadas (como su primera novia Lucía, o como María, que termina suicidándose porque su amante, después de seducirla y desflorarla, decide dejar de tocarla para idolatrar un cuerpo purificado e idealizarla de nuevo). Las representaciones de mujeres muertas -verdadero abono artístico-culminan con la famosa Ofelia del prerrafaelista Sir John Everett Millais (1852, Fig. 9) que inspiró el retrato final de la mujer idealizada -y muerta- por el conde Ciria:

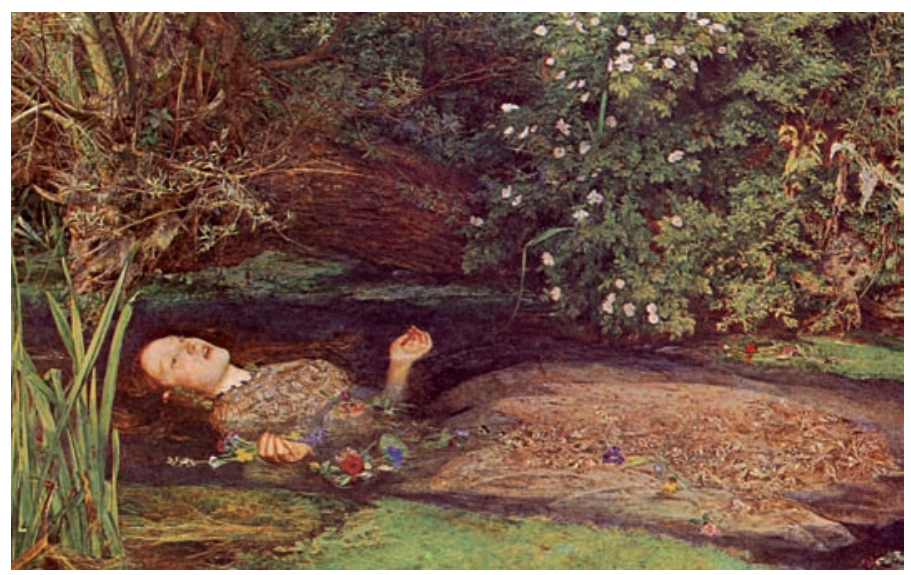

Fig. 9.

Como una góndola mágica el cuerpo de María flotaba sobre el lago de agua mansa y pura, y a su alrededor nadaban con orgullo los pájaros tristes de plumas color de iris, custodiando tan preciada obra de arte. Nunca vió más bella la figura de su ídolo el canto apoliniano. La aureola azul del rostro de la virgen había vuelto a aparecer, y la sagrada euritmia de su belleza helénica brillaba como un fulgor ideal. [...] Y veía flotar en el lago de ondas plateadas manchado de azul, el cuerpo de la diosa, como nenúfar de largas hojas blancas y luminosas. Y la visión de la muerte lo obcecaba cruentamente, confundiéndose con la imagen de Lucía, la virgen pálida y flaca de sus primeros amores. Y las dos muertas amadas se estrechaban desnudas, como 
dos esqueletos de marfil en un antiguo sepulcro de reyes hecho con pórfiro y oro $^{53}$.

Volvemos a encontrar la variación de la mujer muerta acuática, como en Sangre patricia, pero en la novela de Domínici, la muerte de la amada lleva a la transfiguración del protagonista, ya que triunfa el ideal. Sin embargo, los destinos contrarios del conde Ciria y de Tulio Arcos no ilustran, a mi parecer, dos actitudes masculinas obviamente diferentes (uno supera la muerte de su amante, el otro no), sino la misma representación de la mujer, ausente de la vida de los dos hombres, fantasmal, irreal hasta volverse necesariamente un sueño o un recuerdo, producto del espíritu, de la imaginación del hombre.

Las mujeres vaciadas de su sustancia y que han dejado de hablar, se modelan mejor. Solo son cuerpos (cabellera, ojos, bocas, piel blanca), retratos superficiales, fijos y fijados, en dos dimensiones. Es indispensable dominarlas -o domarlas- para que no aspiren, como los vampiros (que cambian de sexo a finales del siglo XIX y se vuelven mujeres, como lo muestra el retrato la Vampira de Munch de 1893, Fig. 10), para que no castren o no hagan perder la cabeza, como las Salomés, las esfinges enigmáticas o las sirenas encantadoras, a los jóvenes hombres que, como Eduardo Doria o Tulio Arcos, acaban matándose por ser corrompidos por Niní o Belén, quienes los afeminaron al volverlos neuróticos, débiles y superficiales. Después de negar y anegar el poder femenino, se precisa afirmar el poder masculino.

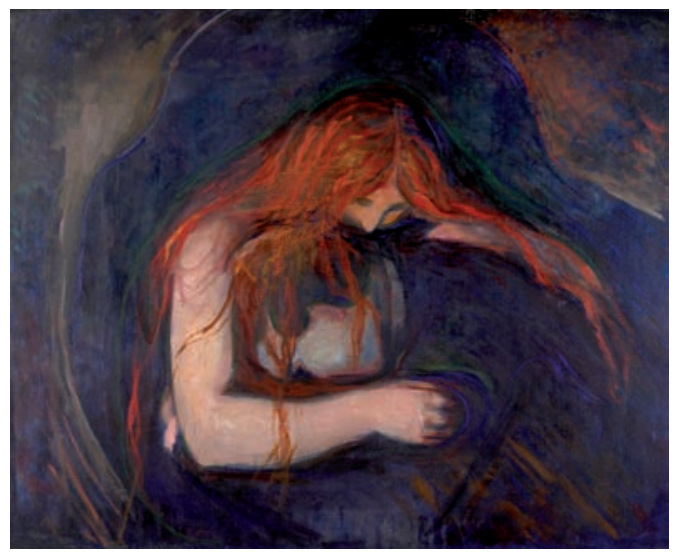

Fig. 10.

53 Pedro César Domínici, op. cit., pp. 120-122. 


\section{LA MUJER-MODELO}

Inspirar y no aspirar: tal podría ser la fórmula mágica de la mujer ideal -e irreal- para el artista masculino modernista. La sobrevaloración de la mujer no es sino otra expresión de la inferiorización de las mujeres, reducidas a un singular esencial e idealizado por los hombres, la mujer, declinada en musa, en obra de arte o en ejemplo de buena conducta: una mujer ideal en tanto que nacida de la idea del hombre ${ }^{54}$, en tanto que existe solamente gracias a él, a su creación, al verbo poético o al dibujo creativo $^{55}$. La mujer, objeto de arte, modelo, modélica, modelada, sirve al creador mientras no se apodere del pincel o de la pluma.

Modelarla implica primero intentar encorsetar a la mujer real dentro de un molde preconcebido, torturándola, si es menester. En La tristeza voluptuosa, el pintor Iriarte, amigo del protagonista, sueńa con realizar el siguiente cuadro para el próximo salón parisino: “El Suplicio: una mujer que ponía una cara convulsiva, mientras los verdugos le quemaban el cuerpo con hierros rojos ardientes" 56 . Más adelante, Eduardo Soria contempla a Niní, que se está desvistiendo, y nota con supremo gozo que "al quitarse el corsé que la oprimía, [...] en su cintura quedaban marcadas, como dibujos hechos sobre cera, las ballenas y los encajes" ${ }^{57}$. Para ser bella -a los ojos de los hombres-, hay que sufrir y moldearse según los criterios de belleza y el canon de representación que se les imponen a las mujeres.

A fin de terminar la obra, hay que modelar el espíritu -aunque tengan muy poco, según los filósofos de la época-. Para que la mujer sea ejemplar, tiene que conformarse con lo que su marido elige por ella,

54 Manuel Díaz Rodríguez, "Paréntesis modernistas o ligero ensayo sobre el modernismo", en Camino de perfección, Caracas, Biblioteca Ayacucho, 1994 [1 $1^{\text {a }}$ edición: 1910], p. 65, evoca de este modo una forma de neoplatonismo: "el verbo contemporáneo de Platón, el único de los antiguos filósofos a quien se ajusta sin violencia nuestro moderno concepto del místico".

55 Anatole France, Le lys rouge, en CEuvres complètes, tomo II, París, La Pléiade, 1987, p. 486, escribe en 1984: “Tu es la matière et moi l'idée, tu es la chose et moi l'âme, tu es l'argile et moi l'artisan".

56 Pedro César Domínici, op. cit., p. 41. La “cara convulsiva” nos recuerda las investigaciones médico-estéticas del doctor Charcot.

57 Ibidem, p. 144. 
sobre todo en materia de lectura. Controlar a Pandora se vuelve una obsesión que se transparenta por ejemplo en los numerosos retratos de lectoras de aquella época, que no reflejan la realidad, ya que no eran tantas las mujeres que se pasaban el tiempo leyendo ${ }^{58}$. Sin embargo, el miedo al bovarysmo, que autoriza solamente libros que educan, se manifiesta en Ídolos rotos y en un cuento de Pedro Emilio Coll, "El Colibrí" (1896), publicado en El Cojo Ilustrado: en la novela de Díaz Rodríguez, las mujeres burguesas -y descerebradas según los Soria- de Caracas anotan secretamente la novela de Marcel Prévost, Les demi-vierges (1894) ${ }^{59}$, que cuenta los daños provocados por la educación moderna y la vida parisina en las jóvenes mujeres ${ }^{60}$; en el cuento de Coll, la esposa, apodada "Colibrî", enjaulada, desobedece a su marido, sin saberlo, al robarle Nana de Zola y leerla, lo que desata la ira del cónyuge ${ }^{61}$. En los retratos de mujeres lectoras, el cuerpo de la mujer es también legible y, muchas veces, funciona como un espejo del libro ${ }^{62}$. El retrato de una Lectora por el venezolano Cristóbal Rojas (1890, Fig. 11) permite identificar a una mujer sabiamente colocada en la intimidad de la casa, entre flores y abanicos decorativos, vestida de azul, color del ideal según los modernistas, pero con un toque de rojo que puede remitir a una lectura "doméstica", sentimental, férreamente controlada, ya que los barrotes de la silla parecen enmarcar el libro, autorizado, aclarado por la luz exterior, que no es sino el espacio masculino.

58 Paulette Silva Beauregard, op. cit., p. 217.

59 Marcel Prévost, Les demi-vierges, París, Mémoire du livre, 2001, 285 pp.

60 Manuel Díaz Rodríguez, op. cit., pp. 164-165. El hermano de Alberto Soria, Pedro, le cuenta que regaló la novela de Prévost a Matildita, su pretendiente, lo que provoca la siguiente reacción de Alberto: "¿Y cómo te atreviste a dar a una muchacha ese libro, que sobre no valer grandemente como obra de arte, es con exceso escabroso?”. Otras lectoras de la novela fueron las Uribe, amigas de Matildita, "vanas, frívolas, [con] sus cabezas de pájaros llenas de aire" (p. 157). Obviamente, las muchachas decentes de Ídolos rotos, María y Rosa Amelia, no han leído la obra del francés.

61 Podemos leerlo acaso como un eco de la polémica obra teatral de Henrik Ibsen, Casa de muñecas (1879), en la que Nora, la esposa, es también comparada por su marido con una alondra y por su padre con una muñeca. Agradezco la sugerencia a Isabelle Touton.

62 Paulette Silva Beauregard, op. cit., p. 233. 


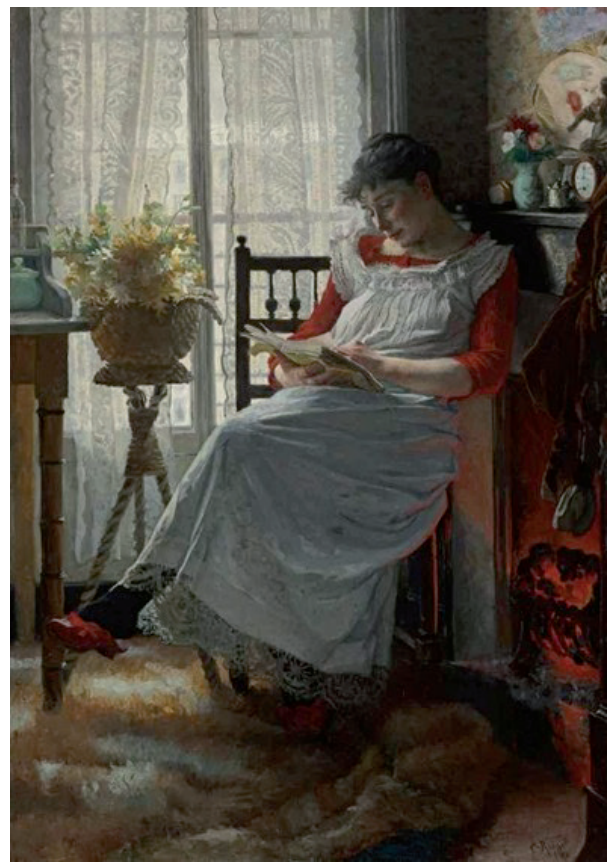

Fig. 11.

En ese contexto, se reactiva el mito de la anti-Salomé, María Magdalena -penitente y también lectora-, figura a la cual le dedica una novela, Miriam de Magdala (1911), el escritor de la Barcelona venezolana, José Manuel Cova Maza. La historia se abre con el consabido retrato de la belleza oriental, de la odalisca de ojos entornados, a la manera de la Judith sensual de Klimt (1901, Fig. 12), de la mujer ricamente adornada de joyas que simbolizan asimismo una especie de cadenas y esposas: "los brazaletes fingían dos sierpes de brillantes escamas; y su collar de perlas era como otra sierpe lumínica enroscada a su garganta"63, amenazando de muerte a la joven, como en el cuento revancha de Darío, "La muerte de Salomé" (1891) ${ }^{64}$, en el que Salomé muere ahogada por su collar-serpiente, que se transforma en animal real. Pero María Magdalena, la cortesana que desprecia a los hombres, se transmuta en penitente seguidora del nuevo profeta, Jesús, quien logra seducirla, sometarla y redimirla. Es asimismo la revancha del hombre sobre la mujer, el triunfo de

63 Ibidem, p. 4.

64 Rubén Darío, Cuentos completos, FCE, México, 1994, p. 224. 
la voz masculina, de la cabeza pensante, del Bautista, sobre el lenguaje sensual del cuerpo femenino domado: es la transfiguración de la mujer fatal en ángel del hogar que ahora salva al hombre gracias a su devoción -de hecho es María Magdalena el primer testigo de la resurrección de Jesús ${ }^{65}$-. El retrato de María Magdalena realizado en 1887 por Alfred Stevens (el modelo fue Sarah Berhnardt, Fig. 13) muestra una total inversión de la figura de Salomé: en la sencillez del vestido blanco, la desnudez del paisaje, aparece una mujer rubia y angelical, sin ninguna joya, acompañada por una cabeza. Sin embargo, ahora, la calavera simboliza el arrepentimiento, transmite el mensaje del memento mori, insistiendo en la vejez y la muerte de la mujer, que parecían imposibles en Salomé, figura de la juventud femenina, triunfante y peligrosa.

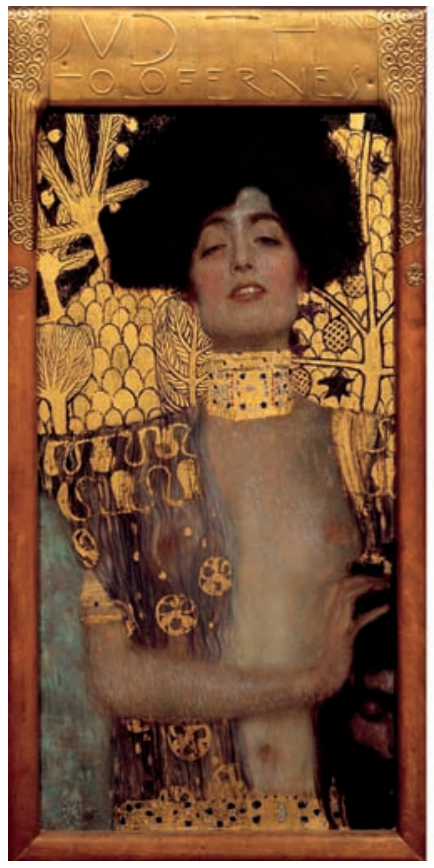

Fig. 12.

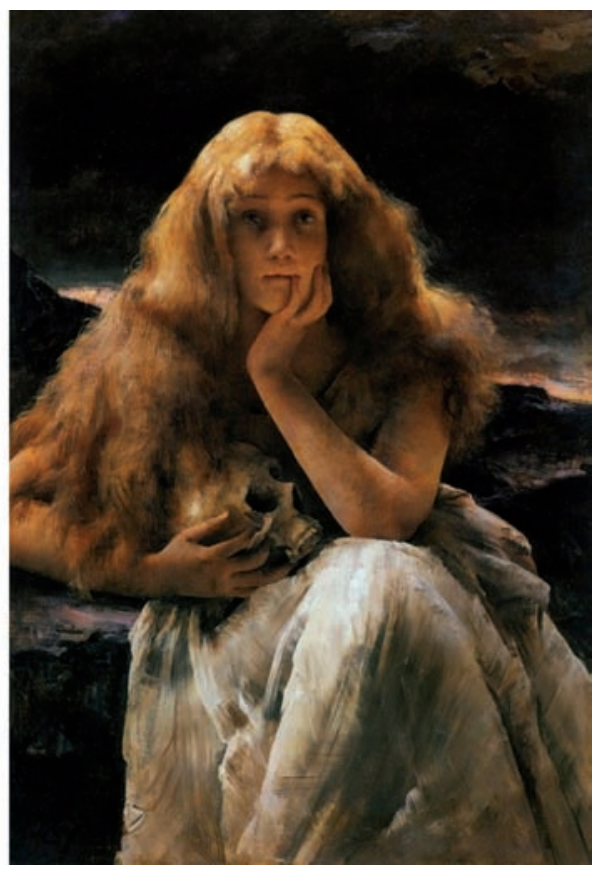

Fig. 13.

65 La novela de Cova Maza desarrolla el siguiente desenlace, que insiste en el papel salvador de la mujer redimida: Miriam le dió de beber a Jesús durante el suplicio y había mezclado secretamente con el líquido un narcótico potente, lo que permitió fingir la muerte. A los tres días, Jesús iba a despertarse: Miriam lo sabía y fue ella quien abrió la tumba para que pudiera salir y "resucitar". 
La idea del hombre como profeta de una nueva religión en la que el arte sería el corazón de la mística invade la literatura y las artes finiseculares ${ }^{66}$. El conde de Ciria de El triunfo del ideal se ve como un nuevo Zaratustra, inspirado por la filosofía de Nietzsche ${ }^{67}$, según la cual hay que superar la moral del bien y del mal ${ }^{68}$. De la misma manera, Alberto Soria, el escultor protagonista de Ídolos rotos, y el pequeño grupo de amigos que lo rodean, piensan difundir la buena nueva del advenimiento de "una belleza nueva, belleza militante, belleza heroica" ${ }^{69}$, igual que Jesús en Miriam de Magdala, "alucinado por la visión fantástica de aquel mundo ideal"70, y que se expresa con parábolas que nadie entiende pero a quien todo el mundo sigue. Sin embargo, todos son víctimas de los mercaderes del Templo y de la incomprensión de una sociedad materialista cuyos ídolos son el dinero y la lujuria. La autorepresentación del artista modernista se plasma en todos aquellos personajes idealistas, incomprendidos, profetas de una nueva religión según la cual, como todas las demás, las mujeres tienen la porción congrua.

La realidad es decepcionante, hay que cambiarla, lo que significa paradójicamente para la mujer mantenerla en la misma situación, fijarla en obras de arte que dejan indeleble la imagen de la mujer ideal, siempre bella y joven, sin pelos ni arrugas, sin palabra ni vida. La mujer solo existe en y a través del ojo del hombre. La reafirmación del poder creador masculino implica representarlo todo desde esta perspectiva y luego pasar de nuevo del cuadro pintado al tableau vivant, entonces filtrado por la visión masculina, creado por el pincel o la pluma del hombre.

La fascinación por el arte y los retratos de mujeres -que no se animanse entiende como la sublimación de la fantasía, la espiritualización del deseo que, al revés, puede ser la erotización de la relación con la obra de arte. La crítica de arte o la contemplación estética se vuelven una suerte

66 En "Paréntesis modernistas o ligero ensayo sobre el modernismo", Manuel Díaz Rodríguez habla del modernismo como de "un movimiento espiritual muy hondo a que involuntariamente obedecieron y obedecen artistas y escritores de escuelas desemejantes". Véase Manuel Díaz Rodríguez, op. cit., p. 69.

67 Pedro César Domínici, op. cit., pp. 19-21.

68 Friedrich Nietzsche, Ainsi parlait Zarathoustra, París, Le livre de poche, 1983.

69 Manuel Díaz Rodríguez, op. cit., p. 196.

70 José Manuel Cova Maza, op. cit., p. 131. 
de onanismo espiritual, como para Des Esseintes. Nuevo Orfeo, el artista saca su inspiración de la ausencia de la mujer, de su negación o su muerte, de su idealización. Tiene que superar la presencia física de la mujer, aniquilar su cuerpo, objeto y lugar de todos los vicios, según la fraternidad médico-artística de la época ${ }^{71}$. En el caso contrario, Orfeo puede perder la cabeza, como el Bautista, Eduardo Doria o Tulio Arcos. En su cuadro Orphée de 1865 (Fig. 14), Gustave Moreau pinta perfectamente la muerte del Poeta de los poetas a manos de una mujer fatal que se convierte en la protagonista del crimen. Para evitar la decapitacion, al artista no le queda otro remedio que cantar, como Dante, a la musa perdida, idealizada en tanto que deshumanizada, esencializada. Así aparece, en El triunfo del ideal, María, la mujer ideal del conde de Cipria, figura mariana, avatar de Beatriz, igual que en la obra del pintor venezolano Cristóbal Rojas, Dante y Beatriz a orillas del Leteo (1889, Fig. 15):

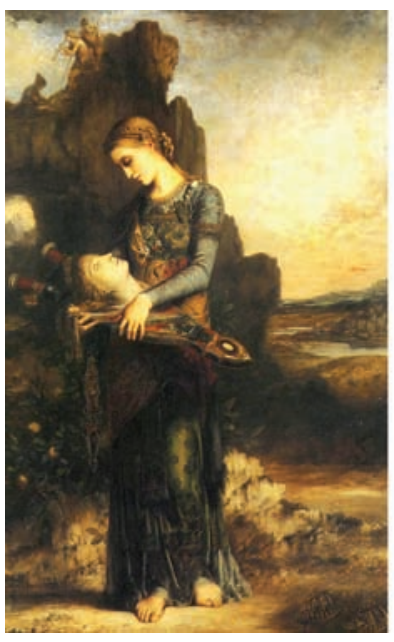

Ilustración 14.

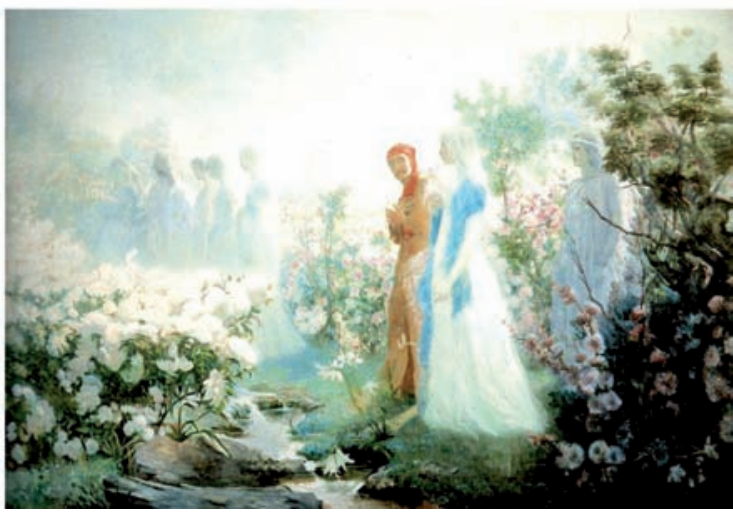

Ilustración 15.

Sus cabellos flotaban sobre sus hombros como espigas de oro, perfumados por el lejano aliento de los rosales; sus ojos claros y profun-

71 Remito en particular a los poemas de Baudelaire (los más famosos) que evocan la corrupción, la podredumbre del cuerpo muerto femenino, como en "Une charogne" (versión trash del memento mori renacentista y barroco), transplantado a la pintura por Gustav-Adolf Mossa en 1906 en un cuadro epónimo. 
dos, miraban como en un sueño. Su nariz era de estatua griega, de impecable virgen dórica. Entre la boca y la barba vagaba una sonrisa indecisa, de piedad y de tristeza; y en la admirable armonía de su rostro había algo inexplicable, como un resplandor azul, pero azul, muy claro, muy tenue, azul de nácar, azul de aurora, de dulzura infinita, de poesía de cosas vaporosas, de paisajes contemplados desde el océano en países vagamente presentidos. Su busto era perfecto. Su cuerpo era como un sublime canto a las formas redentoras de la extinta belleza. Y nada era en ella sensual ni llamaba al deseo $^{72}$.

La mujer etérea, irreal, "azul”, se percibe de forma entrecortada, se diseca, (los ojos, la nariz, la boca), como una Venus anatómica. Convertida en estatua, en un proceso de pigmalionismo al revés, la mujer ideal no habla, no cambia, es impenetrable. La sublimación de la mujer es en realidad su deshumanización, su sustitución por un artefacto estético que, colocado en un museo, plasma la petrificación de su situación en aquel mundo ideal concebido por los artistas modernistas masculinos.

Hablé de museificación en la introducción. Ahora quiero precisar la idea a la luz de la reflexión del filósofo francés Jean-Louis Déotte ${ }^{73}$, especialista en Estética. Cuando se crean los primeros museos públicos en el siglo XVIII ${ }^{74}$, momento en que se inventa la Estética (el juicio sobre lo bello ya no se aplica solamente a la naturaleza sino también al arte), el estatuto de la obra de arte cambia: ya no se destina a un público seleccionado (familia, amigos, visitantes de paso, etc.) en la esfera privada, sino a un público amplio y desconocido en la esfera pública. Lo sagrado se vuelve profano, lo invisible se vuelve visible. El museo público tiene una utilidad social: transmitir un patrimonio artístico seleccionado según criterios estéticos. La obra de arte colocada en un museo se somete al criterio estético de un destinatario desconocido. De ahí la importancia de la selección y de la escenificación, que crean valor y sentido. Con el museo nace la contemplación estética" ${ }^{75}$ y se configura una "sensibilidad

72 Pedro César Domínici, op. cit., pp. 5-6.

73 Jean-Louis Déotte, Le Musée, l'origine de l'esthétique, París, L'Harmattan, 1993.

74 Cronológicamente el del Capitolio, la galería del Luxemburgo -que se desplazará al Louvre-, el British Museum, el de los Oficios, etc.

75 Jean-Louis Déotte, "Le musée n'est pas un dispositif", Cahiers philosophiques, CNDP, 1/2011, 124, pp. 9-22 (p. 10). 
común"76 frente a objetos que, de no ser incorporados en el patrimonio común, se olvidarían. En el museo, las obras sobreviven porque ya no tienen identidad, ni étnica, ni social, ni política ${ }^{77}$, parecen desprenderse de su contexto de producción. Entonces, la estetización a ultranza de la mujer responde a la misma exigencia: quitarle toda forma de identidad, individual, social, cultural, política, y difundir a todos la imagen común que los hombres se hacen -o deben hacerse- de ella. La museificación de la mujer la transforma en objeto de arte estético, que forma parte del patrimonio o de una colección, que fue seleccionado por lo que los conservadores - masculinos hasta hace poco- consideraban como belleza. Se le quita su dimensión sociocultural, su realidad, suspendiéndola en el espacio (de una pared) y en el tiempo. Es una forma de fetichismo y el museo funciona como la antesala burguesa de la heteronomia.

Ya evoqué el caso del doctor Charcot pero son muchos los que aspiran a tener un harén estético, como Des Esseintes. Los que quieren encerrar a su musa en un museo imaginan museos de la Mujer o de la Belleza, como Paul Adam que, en 1907, en la Morale de l'Amour, concibe un museo de la belleza femenina para preservarla, ya que la fealdad y la vejez de las mujeres le dan $\operatorname{asco}^{78}$. Para luchar contra el feminismo, responsable, según él, del afeamiento de la mujer, hay que crear tal institución: "Cela serait possible. Dans un édifice approprié, les plus belles femmes de chaque race s'offriraient à l'admiration de nos intelligences... Il appartiendrait à Paris d'ouvrir ce panthéon de la Beauté et d'y faire paraître les idoles vivantes"79. Para terminar, imagina la organización de una "Fiesta de la Belleza” con la elección de una Diosa que luego desfilaría por París ${ }^{80}$.

Deificada, mitificada, la mujer es una invención de los hombres, que no dejan de instrumentalizarla para hablar indirectamente de otra cosa y, en general, de sí mismos: es la definición de la alegoría (hablar en público

76 Ibidem, p. 14.

77 Ibidem, p. 20.

78 Mireille Dottin-Orsini, op. cit., p. 356: "Esto sería posible. En un edificio adecuado, las más bellas mujeres de cada raza se presentarían para que nuestras inteligencias las admiraran... Le tocaría a París abrir aquel panteón de la Belleza y colocar allí a los ídolos vivos" (la traducción es mía).

79 Paul Adam, La morale de l'amour, París, A. Méricant, 1907, p. 337.

80 Mireille Dottin-Orsini, op. cit., p. 357. 
de otra cosa). De ahí la omnipresencia de mujeres-alegorías como en Ídolos rotos, novela en la que Alberto Soria realiza, o mejor dicho modela, una Venus criolla, símbolo de su patria que termina violada -en todos los sentidos del término- y destruida por soldados ignorantes durante la última revolución. La patria débil, representada por una mujer, encima criolla ${ }^{81}$, es otro de los tópicos cultivados por los modernistas, como José Martí que, en Nuestra América $(1891)^{82}$, opone la virilidad de los dominantes, como los Estados Unidos, a la feminidad de los países latinoamericanos dominados ${ }^{83}$. Lo femenino es definitivamente la explicación más fácil del fracaso masculino.

\section{$* * * * *$}

Por cierto, al cabo de este recorrido sintético, nos podemos preguntar cómo estos elementos definen la literatura venezolana, ya que son constantes de otras literaturas de la época. Pues, por lo menos, sabemos que la literatura venezolana de entresiglos no se singulariza por sus modalidades de representación de las mujeres, criollas o europeas, mulatas o blancas, y entendemos por qué, ya que no se individualizan -la mujer real no interesa- $y$, de cualquier forma, los modernistas no buscan modernizar su situación, muy al contrario. La literatura venezolana se integra, para lo bueno y para lo malo, en una literatura tempranamente globalizada a través de los intercambios continuos entre América y Europa.

De hecho, no olvidemos que el sueño de Paul Adam se ha realizado sobre todo en Venezuela, el país de las misses, donde las mujeres se operan, se mutilan y se moldean según los mismos criterios masculinos de

81 Cabe notar que la mujer que sirve de modelo es una joven mulata, "con su áureo y mate color de canela, el color de la piel de aquella mulatica nacida a la sombra de los cafetales del Tuy, bajo los apamates vestidos de rosadas campánulas vaporosas". Véase Manuel Díaz Rodríguez, op. cit., pp. 170-171. Esta vez, se compara a la mujer mulata con plantas criollas tropicales, según asociaciones corrientes en aquella época entre clima y "raza".

82 José Martí, "Nuestra América”, en Nuestra América, Caracas, Biblioteca Ayacucho, 1977, pp. 31-39.

83 Paulette Silva Beauregard, "La feminización del héroe moderno y la novela en Lucía Jérez y El hombre de hierro", Revista de critica literaria latinoamericana, XXVI, 52, 20 semestre (2000), pp. 135-151. 
belleza, todavía imperantes, para satisfacer las exigencias de un concurso que aviva aún el orgullo nacional. La "mitificación opresiva" ${ }^{84}$ de la mujer sigue vigente, tributaria de la mitología de la feminidad finisecular. Pues, me temo que, desde hace más de un siglo, se producen y se reproducen estereotipos femeninos sin la menor variación.

84 Luis Martínez Victorio, op. cit., p. 602. 